\title{
Влияние срока и способа хранения индюшиных яиц на результаты инкубации
}

\author{
Колокольникова Т.Н., кандидат сельскохозяйственных наук, ведущий научный сотрудник
} Сибирский НИИ птицеводства (СибНИИП) - филиал ФГБНУ «Омский аграрный научный центр»

\begin{abstract}
Аннотащия: Хранение инкубационных яии сопряжено с изменением их внутреннего состава и состояния зародыша. Изучено множество приемов сохранения качества инкубационного яйца и жизнеспособности эмбриона. Однако, как оказалось, не все приемы хранения подходят для каждого из видов птицил. Так, прием хранения индюииных инкубационных яии острым полюсом бберх позболяет повысить их быбодимость на 0,81-1,63\% (неделя хранения), либо нивелировать пагубнье последствия биохимических изменений 6 яйце и сохранить быводимость яии на уробне 85,20-90,36 и 80,10-80,9\% через 2 и 3 недели хранения соответственно. Использование герметичной упакобки для хранения индюииных инкубационных яии без достаточного времени проветривания прибодит к снижению результатов инкубации, причем при увеличении срока хранения отрииательный эфрфект усиливается и быбодимость яии снижается с 89,53-91,22\% (неделя хранения) до 27,08-46,86\% (3 недели хранения). В любом случае сроки хранения 2 и 3 недели отрицательно сказываются на качестве суточного молодняка, что быражается $\mathfrak{b}$ убеличении жибой массы на 0,05-1,45 и 0,30-4,67\%, а также уменьшении длины тела на 2,44-3, 11 и 3,08-3,37\% соответственно.
\end{abstract}

Ключебые слова: хранение индюшиных яии, быбодимость яии, жибая масса суточных индюшат, длина тела суточных индюшат.

Введение. В практическом птицеводстве нередко возникает необходимость увеличения срока хранения инкубационных яиц сверх рекомендованных нормативов. До какого уровня снижается выводимость яиц при увеличении срока хранения? Как сохранить жизнеспособность эмбриона? Учеными проведено множество исследований в данном направлении, основная их часть - на яйцах кур. На яйцах индеек исследований сравнительно мало.

После снесения и остывания В яйце начинаются негативные преобразования, и чем больше срок хранения до инкубации, тем ниже жизнеспособность эмбриона. Скорость и сила отрицательного влияния срока хранения зависит от микробного фона, температуры, влажности, газового состава среды, в которой хранятся яйца до инкубации.
В руководстве по инкубации яиц индеек отмечено, что при необходимости хранения индюшиных яиц свыше 6 суток для сохранения их инкубационных качеств можно использовать такие приемы, как снижение температуры до 8-12 ${ }^{\circ}$; хранение в упаковке без доступа воздуха и в инертных газах; периодический прогрев яиц со 2-го дня хранения каждые 5 дней до $38^{\circ} \mathrm{C}$ в течение 5 часов; поворот яиц на $90^{\circ}$ один раз в день после 5 дней хранения. Данные приемы позволяют хранить индюшиные яйца до 15-20 суток без существенного изменения их инкубационных качеств [1-3].

Помимо описанных выше, предложен еще один прием, способствующий удержанию зародыша на безопасном расстоянии от подскорлупных оболочек, способных его травмировать - хранение острым полюсом вверх $[4,5]$.
В проведенных ранее исследованиях на яйцах кур мясного кросса установлено, что герметичная упаковка яиц способствует замедлению скорости распада витаминов, нарушения кислотно-щелочного баланса белка и желтка, процесса «старения» содержимого яиц за счет ограничения потери $\mathrm{CO}_{2}$, предотвращению повторного обсеменения и сдерживанию роста имеющихся микроскопических грибов (Asp. flavus, Penicillum sp.) на поверхности яиц даже при 3-недельном хранении, благодаря ограничению доступа кислорода. Наилучшие результаты получены при хранении яиц острым полюсом вверх в герметичной упаковке. Выводимость яиц и вывод молодняка увеличивались при хранении в течение 1, 2 и 3 недель на 2,8-4,3; 6,4-10,4 ( $<<0,05)$ и $9,5-11,7 \%(P<0,05)$ и 4,8-5,4; 6,5- 
$7,9$ и 7,6-12,1\% ( $\mathrm{P}<0,05)$ соответственно [6,7].

Поиск возможностей улучшения экономических показателей производства и разработка способов сохранения качества инкубационных яиц индейки является актуальной задачей.

Цель исследования - изучить влияние приемов и сроков хранения инкубационных яиц индеек на результаты инкубации и качество суточного молодняка.

Материал и методика исследований. Проведено 2 опыта на яйцах индеек родительского стада кросса Hybrid Converter в ОП Ачаирский (отбор яиц и хранение), в ООО «Морозовская птицефабрика» и ООО «Абсолют-Агро». Для проведения каждого опыта методом аналогов по массе от одного родительского стада комплектовали 12 групп по 200 штук яиц в каждой. Группы отличались сроками и приемами хранения (табл. 1).

Яйца групп ТУ и ОУ упаковывали в бугорчатых прокладках в полиэтиленовые пакеты, имеющие застежку-бегунок и клапан, через который откачивали воздух до обтягивания ячеек пакетом. Яйца всех групп хранили до инкубации при температуре $15-16^{\circ} \mathrm{C}$ и влажности $70-75 \%$. На инкубацию яйца всех групп закладывали в пределах одной зоны инкубатора.

\section{Результаты исследований} и их обсуждение. Потеря массы яиц увеличивалась с увеличением срока хранения. При хранении острым полюсом вверх яйца теряли влагу медленнее, чем хранившиеся тупым полюсом вверх. Герметичная упаковка также сдерживала потерю влаги из яиц (табл. 2).

Наиболее подготовленными к выводу на момент переноса в обоих опытах были эмбрионы групп O1, наименее подготовленными ТУЗ (табл. 3).

\section{Таблица 1. Схема исследования}

Срок

хранения,

Прием хранения яиц

$$
\text { нед. }
$$
тупым острым без герметичной упаковки

1

2

3 $\mathrm{Tl}$

$\mathrm{T} 2$

01

$\mathrm{O} 2$

$\mathrm{O} 3$

$\mathrm{T} 3$

Примечание к обозначению групп: Т- хранение тупым полюсом вверх; О - хранение острым полюсом вверх; $\mathbf{Y}$ - хранение в герметичной упаковке; 1,2 и 3 - срок хранения яиц, нед.

\begin{tabular}{|c|c|c|c|c|}
\hline \multirow{2}{*}{$\begin{array}{c}\text { Срок хранения, } \\
\text { нед. }\end{array}$} & \multicolumn{4}{|c|}{ Прием хранения } \\
\hline & $\mathbf{T}$ & Ty & $\mathbf{0}$ & oy \\
\hline \multicolumn{5}{|c|}{ Опыт 1} \\
\hline 1 & 0,72 & 0,49 & 0,71 & 0,48 \\
\hline 2 & 1,12 & 0,67 & 0,89 & 0,64 \\
\hline 3 & 1,45 & 0,80 & 1,35 & 0,75 \\
\hline \multicolumn{5}{|c|}{ Onblт 2} \\
\hline 1 & 0,80 & 0,67 & 0,70 & 0,64 \\
\hline 2 & 1,19 & 0,83 & 1,02 & 0,78 \\
\hline 3 & 1,46 & 1,03 & 1,39 & 0,98 \\
\hline
\end{tabular}

Таблица 3. Количество эмбрионов I категории развития на 24,5 сутки, \%

\begin{tabular}{|c|c|c|c|c|}
\hline \multirow{2}{*}{ Срок хранения яиц, нед. } & \multicolumn{4}{|c|}{ Группа } \\
\hline & $\mathbf{T}$ & TY & $\mathbf{O}$ & oy \\
\hline \multicolumn{5}{|c|}{ Опыт 1} \\
\hline 1 & 92,66 & 91,43 & 93,40 & 91,74 \\
\hline 2 & 83,53 & 82,21 & 85,42 & 83,75 \\
\hline 3 & $64,62^{*, \#}$ & $55,42^{* * \#}$ & $66,33^{\prime \prime \#}$ & $56,14^{* * \#}$ \\
\hline \multicolumn{5}{|c|}{ Oпыт 2} \\
\hline 1 & 95,88 & 94,04 & 96,30 & 94,98 \\
\hline 2 & $85,17^{*}$ & $82,25^{*}$ & $87,98^{*}$ & $83,89^{*}$ \\
\hline 3 & $70,94^{\star, \#}$ & $51,02^{*, \#, a}$ & $71,76^{*, \#}$ & $52,35^{*, \#, a}$ \\
\hline
\end{tabular}

Примечания: * - разность достоверна с группами Т1, ТУ1, О1 и ОУ1 при P<0,05-0,001. \# - разность достоверна с группами Т2, ТУ2, О2 и ОУ2 при $\mathrm{P}<0,05-0,001$.

а - разность достоверна с группами Т3 и О3 при $\mathrm{P}<0,001$.

Увеличение срока хранения яиц сверх 1 недели в 1-м и 2-м опытах привело к уменьшению количества эмбрионов I категории развития к моменту переноса яиц на вывод. Данный показатель снижался, относительно одной недели хранения: в группах, хранившихся без упаковки 2 недели, на 9,13-7,98 и 10,71-8,32\% ( $<<0,05-0,001) ; 3$ недели - на 28,04$27,07(\mathrm{P}<0,001)$ и 24,94-24,54\% $(\mathrm{P}<0,001)$; в группах, хранившихся в упаковке 2 недели - на 9,22-7,99 и 11,79-11,09\% ( $<<0,001), 3$ недели - на 36,01-35,60 (P<0,001) и $43,02-42,63 \%(P<0,001)$. Отмечено отставание по количеству эмбрионов I категории в группах с трехнедельным хранением в сравнении с группами с двухнедельным хранением яиц без упаковки на 18,91-19,09 ( $<<0,05-0,01)$ и 14,23$16,2 \%(P<0,01-0,001)$, в упаковке на 26,79-27,61 (P<0,01-0,001) и 31,23-31,54\% ( $<<0,01-0,001)$.

При хранении яиц острым полюсом вверх в обоих опытах получен положительный результат в сравнении с группами, где яйца хранили тупым полюсом вверх. Так, в группах, хранившихся острым полюсом вверх 1, 2 и 3 недели без упаковки, эмбрио- 


\begin{tabular}{|c|c|c|c|c|c|c|c|c|c|c|c|c|}
\hline \multirow{2}{*}{ Показатель } & \multicolumn{12}{|c|}{ Группа } \\
\hline & $\mathbf{T 1}$ & TY1 & 01 & OY 1 & T2 & TY2 & 02 & Oy2 & T3 & Ty3 & 03 & оуз \\
\hline $\begin{array}{l}\text { Оплодотворенность } \\
\text { яиц }\end{array}$ & 98,98 & 98,96 & 98,99 & 98,99 & 98,48 & 98,49 & 98,49 & 98,48 & 98,47 & 97,96 & 98,49 & 97,95 \\
\hline Выводимость яиц & 89,74 & 89,53 & 91,37 & 90,31 & 85,13 & $\underset{\#}{81,12}$ & 85,20 & $\underset{c, d}{83,08}$ & $\underset{\substack{\#, \# \# \\
72,54}}{ }$ & 27,08 & $\underset{\#}{80,10}$ & 31,41 \\
\hline Вывод молодняка & 85,79 & 84,46 & 86,93 & 85,86 & 80,81 & $\underset{\mathrm{a}, \mathrm{cc}, \mathrm{d}}{76,88}$ & 81,91 & 79,80 & 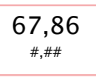 & 21,43 & $\underset{\mathrm{a}, \mathrm{cc}, \mathrm{d}}{76,88}$ & 26,67 \\
\hline \multicolumn{13}{|c|}{ Отходы инкубации: } \\
\hline $\begin{array}{l}\text { неоплодотворенные } \\
\text { яйца }\end{array}$ & 1,02 & 1,04 & 1,01 & 1,01 & 1,52 & 1,51 & 1,51 & 1,52 & 1,54 & 2,04 & 1,51 & 2,05 \\
\hline $\begin{array}{l}\text { замершие до } 48 \text { ч } \\
\text { инкубации }\end{array}$ & 1,02 & 1,04 & 0,50 & 1,01 & 1,01 & 1,51 & 1,01 & 1,52 & $\begin{array}{c}5,61 \\
\#, \# \#\end{array}$ & 20,41 & 2,51 & 20,00 \\
\hline кровяное кольцо & 4,56 & 3,11 & 4,02 & 3,03 & 4,54 & $\underset{B, d}{8,54}$ & 4,52 & $\underset{B, d}{7,57}$ & $\underset{B, d}{7,65}$ & 33,16 & $\underset{B, d}{7,54}$ & 31,28 \\
\hline замершие & 1,02 & 1,04 & 0,50 & 0,51 & 1,52 & 2,01 & 2,01 & 1,52 & $\begin{array}{c}5,10 \\
\#, f\end{array}$ & $\begin{array}{c}7,66 \\
\text { вв,cсc,ddd,\#\# }\end{array}$ & 2,51 & $\begin{array}{c}6,67 \\
\text { вв,ссc, ddd,\#\# }\end{array}$ \\
\hline задохлики & 3,54 & 5,17 & 3,52 & 5,04 & 7,57 & 6,53 & 7,03 & 6,05 & $8,67^{a, c}$ & $10,20^{\mathrm{aa}, \mathrm{cc}}$ & 7,04 & $9,23^{a, c}$ \\
\hline $\begin{array}{l}\text { некондиционный } \\
\text { молодняк }\end{array}$ & 3,05 & 4,14 & 3,52 & 3,54 & 3,03 & 3,02 & 2,01 & 2,02 & 3,57 & 5,10 & 2,01 & 4,10 \\
\hline
\end{tabular}

Примечания: 1. Разность достоверна с группой Т1: $\mathrm{P}<0,05$ - а; $\mathrm{P}<0,01$ - аа.

2. Разность достоверна с группой ТУ1: $\mathrm{P}<0,05$ - в; $\mathrm{P}<0,01$ - вв.

3. Разность достоверна с группой О1: $\mathrm{P}<0,05$ - с; $\mathrm{P}<0,01$ - сс; $\mathrm{P}<0,001$ - ссс.

4. Разность достоверна с группой ОУ1: $\mathrm{P}<0,05$ - d; $\mathrm{P}<0,001$ - ddd.

5. Разность достоверна с группами Т2 и ОУ2: $\mathrm{P}<0,05$ - f.

6. Разность в группах ТУЗ и ОУЗ достоверна со всеми остальными группами: $\mathrm{P}<0,001$ - $^{\text {**t* }}$.

7. Разность достоверна с группами Т1, ТУ1, О1 и ОУ1: Р<0,05-0,001 - \#.

8. Разность достоверна с группами Т2, ТУ2, О2 и ОУ2: Р <0,05-0,001 - \#.

нов I категории было больше на 0,74-0,42; 1,89-2,81 и 1,71-0,82\%, при хранении в упаковке - на 0,31-0,94; 1,54-1,64 и 0,72-1,33\% соответственно.

В подобном исследовании на яйцах мясных кур наилучший результат получен при хранении яиц острым полюсом вверх в герметичной упаковке. Яйца после обработки формалином проветривали 7 ч, а затем герметично упаковывали. То же делали и с яйцами индеек. Однако яйцо индеек имеет более толстую скорлупу и подскорлупную пленку. При обработке яиц перед размещением на хранение формалин проникает в поры скорлупы. Вероятно, 7-часового проветривания для яиц индеек недостаточно, и следы формалина остаются в порах. После упаковки остаточный формалин путем диффузии проникает вглубь яйца и, являясь токсичным для эмбриона, угнетает его развитие в процессе инкубации.

Таким образом, герметичная упаковка оказала отрицательное влияние на качество индюшиных инкубационных яиц в 1-м и 2-м опытах. В яйцах, хранившихся в упаковке как тупым, так и острым полюсом вверх, эмбрионов I категории было меньше при сроке хранения 1 неделя на 1,231,66 и 1,84-1,32\%; 2 недели - на 1,32-1,67 и 2,92-4,09\%; 3 недели - на 9,20-10,19 и 19,92-19,41\% ( $<<0,05-0,001)$, чем в группах-аналогах, хранившихся без упаковки.

Таким образом, хранение индюшиных яиц острым полюсом вверх оказывало положительное влияние на сохранность их инкубационных качеств в течение 1-3 недель. Хранение в герметичной упаковке без достаточного времени проветривания после обработки формалином отрицательно сказывается на развитии эмбрионов. Наибольший отрицательный эффект получен при трехнедельном хранении яиц в упаковке.

Срок хранения яиц оказал основное влияние и на результаты инкубации, причем наилучшие результаты были получены в груп- пах Т1, ТУ1, О1 и ОУ1 (табл. 4, 5). С увеличением срока хранения яиц результаты инкубации достоверно снижались ( $<<0,05-0,001)$.

Размещение яиц на хранение острым полюсом вверх оказало положительное влияние на сохранение их инкубационных качеств, особенно при увеличении срока хранения. В опыте 1 при хранении яиц острым полюсом вверх без упаковки и в упаковке в течение 1, 2 и 3 недель были выше выводимость яиц - на 1,630,78; 0,07-1,96 и 7,56-4,33\%, вывод молодняка - 1,14-1,40; 1,10 2,92 и 9,02-5,24\% соответственно; в опыте 2 - на 0,81-0,78; 0,400,61 и 3,24-4,17\% и на 1,58-0,62; 0,40-0,49; 3,17-5,85\%. Наибольшее положительное влияние расположения яиц острым полюсом вверх отмечено при трехнедельном сроке хранения.

Герметичная упаковка оказала отрицательное влияние на результаты инкубации. Отрицательный эффект, как описано выше, получен из-за остаточного фор- 
малина в порах скорлупы яиц, который путем диффузии в процессе хранения попал в содержимое яйца. С увеличением срока хранения отрицательный эффект усиливался. В опыте 1 показатели выводимости яиц и вывода молодняка были ниже при хранении яиц в упаковке: в течение 1 недели - на 0,21-1,06 и 1,331,07\%; 2 недель - на 4,01-2,12 и 3,93-2,11\%; 3 недель $(\mathrm{P}<0,001)$ на 45,46-48,69 и 46,43-50,21\% в сравнении с группами, которые не упаковывали перед хранением. По количеству отходов инкубации группы, хранившиеся без упаковки и в упаковке в течение 1 недели, отличались незначительно. Однако при двухнедельном хранении в группах ТУ2 и ОУ2 в сравнении с группами Т2 и О2 количество всех категорий отходов инкубации было больше на 0,47-5,43\%, за исключением некондиционного молодняка, количество которого было незначительно меньше, вероятно, за счет увеличения количества «задохли- ков». При хранении в герметичной упаковке в течение 3 недель в сравнении с группами-аналогами Т3 и О3 достоверно ( $<<0,001)$ увеличилось количество отходов инкубации категории «замершие до 48 ч инкубации» на 14,8$17,49 \%$, «кровяное кольцо» - на 25,51-23,74\%. Увеличение других категорий отходов инкубации находилось в пределах 0,5-4,16\% и было недостоверным.

В опыте 2 показатели выводимости яиц и вывода молодняка были ниже при хранении яиц в упаковке, чем без нее, в течение 1 недели на 3,13-3,16 и 3,023,98\%; 2 недель - на 4,80-4,59 и 4,23-4,14\%; 3 недель ( $<<0,001)$ на 35,04-34,11 и 37,54-34,86\%. Количество отходов инкубации в группах, хранившихся в упаковке, было выше на 0,02-2,28\%, чем в группах хранившихся без упаковки. Однако в яйцах, хранившихся в упаковке 1 и 2 недели, достоверной разности с группами, хранившимися тот же срок без упаковки по отходам инкубации не отмечено. При хранении яиц в упаковке в течение 3 недель отмечено достоверное $(\mathrm{P}<0,001)$ увеличение отходов инкубации категории «замершие до 48 ч инкубации» на 7,01-6,88\%, «замершие» на 7,42-6,28\%, «задохлики» - на 20,87-19,58\% в сравнении с группами ТЗ и О3.

По живой массе суточных индюшат в опыте 1 достоверной разности между группами не установлено (табл. 6). В опыте 2 индюшата групп со сроком хранения яиц 3 недели были достоверно тяжелее на 2,23-2,91 г (3,57-4,67\%) и 1,562,10 г (2,47-3,32\%) в сравнении с группами, где яйца хранили 1 $(\mathrm{P}<0,001)$ и $2(\mathrm{P}<0,05-0,001)$ недели. Прослеживается зависимость данного показателя от срока и приема хранения. Чем больше срок хранения, тем больше живая масса суточных индюшат. Живая масса индюшат из яиц, хранившихся в упаковке, больше, чем из яиц, хранившихся без нее.

Длина тела суточных индюшат в опыте 1 была наибольшей в груп-

\begin{tabular}{|c|c|c|c|c|c|c|c|c|c|c|c|c|}
\hline \multirow{2}{*}{ Показатель } & \multicolumn{12}{|c|}{ Гpynna } \\
\hline & T1 & TY1 & 01 & OY1 & T2 & TY2 & $\mathbf{O 2}$ & OY2 & T3 & Tуз & 03 & oy3 \\
\hline Оплодотворенность яиц & 98,81 & 98,43 & 98,81 & 98,13 & 98,81 & 98,84 & 98,81 & 98,52 & 98,02 & 98,86 & 98,02 & 98,55 \\
\hline Выводимость яиц & 93,57 & 90,44 & 94,38 & 91,22 & 89,96 & $\begin{array}{c}85,16 \\
\text { aa,ccc,d }\end{array}$ & 90,36 & $\begin{array}{r}85,77 \\
\text { aa,ccc,d }\end{array}$ & $\begin{array}{c}77,73 \\
\#, \# \#\end{array}$ & $\underset{\substack{\text { shtox } \\
42,69}}{42,69}$ & $\begin{array}{c}80,97 \\
\#, f f, j j\end{array}$ & $\underset{* * \star *}{46,86}$ \\
\hline Вывод молодняка & 89,29 & 86,27 & 90,87 & 86,89 & $\underset{c}{84,92}$ & $\begin{array}{c}80,69 \\
\text { aа, сc }\end{array}$ & 85,32 & $\underset{\text { aa,cc }}{81,18}$ & $\begin{array}{c}70,24 \\
\#, \# \#\end{array}$ & 32,70 & $\begin{array}{c}73,41 \\
\#, \# \#\end{array}$ & $\underset{* * \star *}{38,55}$ \\
\hline \multicolumn{13}{|c|}{ Отходы инкубации: } \\
\hline неоплодотворенные яйца & 1,19 & 1,57 & 1,19 & 1,87 & 1,19 & 1,16 & 1,19 & 1,48 & 1,98 & 1,14 & 1,98 & 1,45 \\
\hline замершие до 48 ч инкубации & 0,79 & 2,75 & 0,79 & 2,25 & 1,59 & $\begin{array}{c}3,47 \\
a, c\end{array}$ & 1,59 & $\underset{a, c}{3,32}$ & $\begin{array}{l}5,16 \\
\text { aa,cc,f,j, }\end{array}$ & $\begin{array}{l}12,17 \\
\#, \#, \# \# \#\end{array}$ & $\begin{array}{l}4,76 \\
\text { aа,сc,f,j }\end{array}$ & $\begin{array}{l}11,64 \\
\#, \# \#, \# \# \#\end{array}$ \\
\hline кровяное кольцо & 0,79 & 1,18 & 0,79 & 1,12 & 1,59 & 1,54 & 1,59 & 1,48 & 2,38 & 1,90 & 1,59 & 2,55 \\
\hline замершие (9-24,5 сутки) & 1,98 & 1,96 & 1,59 & 1,87 & 1,98 & 2,70 & 1,98 & 2,58 & 4,37 & $\begin{array}{l}11,79 \\
\#, \# \#, \# \# \#\end{array}$ & 3,17 & $\begin{array}{c}9,45 \\
\#, \# \#, \# \# \#\end{array}$ \\
\hline задохлики & 2,79 & 3,52 & 2,39 & 3,37 & 4,76 & $\begin{array}{c}6,96 \\
a, c\end{array}$ & 4,36 & $\begin{array}{c}6,64 \\
a, c\end{array}$ & $\underset{\#, \mathrm{f}, \mathrm{j}}{9,92}$ & 30,79 & $\underset{\#, f, j}{9,14}$ & $\underset{* * \star *}{28,72}$ \\
\hline некондиционный молодняк & 3,17 & 2,75 & 2,38 & 2,63 & 3,97 & 3,48 & 3,97 & 3,32 & $\underset{c}{5,95}$ & $\underset{\#, \# \#}{9,51}$ & $\underset{c}{5,95}$ & $\begin{array}{c}7,64 \\
\#, g, k\end{array}$ \\
\hline
\end{tabular}

Примечание: 1. Разность достоверна с группой Т1: $\mathrm{P}<0,05$ - а; P $<0,01$ - аа.

2. Разность достоверна при $\mathrm{P}<0,05$ с группой: ОУ1 - d; ТУ2 - g; ОУ2 -

3. Разность достоверна с группой О1: $\mathrm{P}<0,05$ - с; $\mathrm{P}<0,01$ - сс; $\mathrm{P}<0,001$ - ссс

4. Разность достоверна с группой Т2: $\mathrm{P}<0,05$ - f; $\mathrm{P}<0,01$ - ff.

5. Разность достоверна с группой О2: $\mathrm{P}<0,05-\mathrm{j} ; \mathrm{P}<0,001-$ jj.

7. Разность в группах ТУз и ОУЗ достоверна со всеми остальными группами: $\mathrm{P}<0,001$ - *** .

8. Разность достоверна с группами Т1, ТУ1, О1 и ОУ1: Р <0,05-0,001 - \#.

9. Разность достоверна с группами Т2, ТУ2, О2 и ОУ2: Р <0,05-0,001 - \#

10. Разность достоверна с группами Т3 и О3: Р <0,05-0,001 - \#\#. 


\begin{tabular}{|c|c|c|c|c|}
\hline \multirow{2}{*}{$\begin{array}{c}\text { Срок } \\
\text { хранения, нед. }\end{array}$} & \multicolumn{4}{|c|}{ Прием хранения } \\
\hline & $\mathbf{T}$ & TY & $\mathbf{0}$ & oy \\
\hline \multicolumn{5}{|c|}{ Oпыт 1} \\
\hline \multicolumn{5}{|c|}{ Живая масса, г } \\
\hline 1 & $62,03 \pm 0,51$ & $62,63 \pm 0,53$ & $62,33 \pm 0,54$ & $62,29 \pm 0,69$ \\
\hline 2 & $62,59 \pm 0,47$ & $62,73 \pm 0,51$ & $62,39 \pm 0,44$ & $62,32 \pm 0,42$ \\
\hline 3 & $62,78 \pm 0,50$ & $62,82 \pm 0,96$ & $62,84 \pm 0,41$ & $62,65 \pm 0,57$ \\
\hline \multicolumn{5}{|c|}{ Длина тела, мм } \\
\hline 1 & $203,10 \pm 0,77$ & $202,98 \pm 0,82$ & $203,71 \pm 0,81$ & $203,79 \pm 1,06$ \\
\hline 2 & $197,22 \pm 0,81^{*}$ & $197,30 \pm 0,91^{*}$ & $198,73 \pm 0,98^{\prime \prime}$ & $197,45 \pm 0,93$ \\
\hline 3 & $196,85 \pm 0,83^{\prime \prime}$ & $196,24 \pm 0,85^{*}$ & $196,85 \pm 0,89^{\prime \prime}$ & $196,92 \pm 1,47^{\prime}$ \\
\hline \multicolumn{5}{|c|}{ Oпыт 2} \\
\hline \multicolumn{5}{|c|}{ Живая масса, г } \\
\hline 1 & $62,47 \pm 0,35$ & $62,42 \pm 0,37$ & $61,87 \pm 0,40$ & $62,11 \pm 0,38$ \\
\hline 2 & $63,14 \pm 0,39$ & $63,23 \pm 0,40$ & $62,52 \pm 0,41$ & $63,04 \pm 0,40$ \\
\hline 3 & 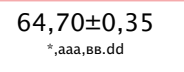 & $\begin{array}{l}65,33 \pm 0,41 \\
\text { *,aaa, }, 8 B,, c c . d d d\end{array}$ & $\underset{\substack{*, a, c c . d \\
64,23 \pm 0,39}}{6}$ & $\begin{array}{c}65,01 \pm 0,40 \\
* \text { *aaa, Bв,ccc.ddd }\end{array}$ \\
\hline \multicolumn{5}{|c|}{$\begin{array}{l}\text { Примечания: 1. Разность с группами Т1, ТУ1, О1 и ОУ } 1 \text { достоверна: } \mathrm{P}<0,001 \text { - *. } \\
\text { 2. Разность С группой Т2 достоверна: } \mathrm{P}<0,05 \text { - а; } \mathrm{P}<0,001 \text { - ааa. } \\
\text { 3. Разность С группой ТУ2 достоверна: } \mathrm{P}<0,01 \text { - в8; } \mathrm{P}<0,001 \text { - ввв. } \\
\text { 4. Разность С группой О2 достоверна: } \mathrm{P}<0,01 \text { - сс; } \mathrm{P}<0,001 \text { - ссс. } \\
\text { 5. Разность с группой ОУ2 достоверна: } \mathrm{P}<0,05 \text { - } \text {; } \mathrm{P}<0,01 \text { - dd; } \mathrm{P}<0,001 \text { - ddd. }\end{array}$} \\
\hline
\end{tabular}

пах Т1, О1, ТУ1 и ОУІ и достоверно $(\mathrm{P}<0,001)$ уменьшалась при увеличении срока хранения яиц до 2 недель на 4,98-6,34 мм (2,44-3,11\%); до 3 недель - на 6,25-6,87 мм (3,08-3,37\%). Между группами со сроком хранения 2 и 3 недели достоверной разности не отмечено.

При трехнедельном хранении яиц живая масса индюшат была наибольшей, а их длина - наименьшей в сравнении с другими сроками хранения.

Длина тела суточного молодняка - критерий оценки его качества. Большая живая масса и меньшая длина свидетельствуют о худшем использовании содержимого желточного мешка и менее интенсивном развитии эмбриона [8].

Достоверной разности по длине тела между группами, отличающимися приемом хранения при сроках 1, 2 и 3 недели, не отмечено. Таким образом, на качество суточного молодняка большее влияние оказывает срок хранения, а не прием.

Заключение. Выводимость яиц и вывод молодняка снижаются при сроке хранения 2 не- дели на 3,61-8,41 и 4,37-7,58\%, 3 недели - на 11,27-62,45и 10,05$63,03 \%$ относительно одной недели хранения. При этом живая масса суточного молодняка больше на 0,10-1,5 и 0,30-4,67\% $(\mathrm{P}<0,001)$, а длина тела - меньше на 2,44-3, 11 и 3,08-3,37\%, то есть качество молодняка ниже.

Прием хранения индюшиных яиц острым полюсом вверх в течение 1,2 и 3 недель является оптимальным и позволяет увеличить выводимость яиц на 0,78 1,63; 0,07-1,96 и 3,24-7,56\%; вывод молодняка - на 0,62-1,58; 0,40-2,92; 3,17-9,02\% соответственно в сравнении с группами, хранившимися тупым полюсом вверх.

Хранение яиц индейки в герметичной упаковке 1, 2 и 3 недели снижает их выводимость на 0,213,$16 ; 2,12-4,80$ и 34,11-48,69\%, вывод молодняка - на 1,07-3,98; 2,1 1-4,23 и 34,86-50,21\%.

Выражаю огромную благодарность сотрудникам птицеводческих предприятий, оказавших помощь и поддержку при проведении данных исследований: Ко- локольникову Н.В., Шабашевой Е.И., Амиранашвили Е.И., Мезенцеву Д.И., Панову В.В.

\section{Литература}

1. Руководство по инкубации яиц индеек / Прокудина Н.А., Дуюнова А.А., Огурцова Н.С. [и др.]. - Под общ. ред. Терещенко А.В. - Борки, 2007. - 106 с. 2. Дядичкина Л.Ф., Гупало И.М., Позднякова Н.С., Мелехина Т.А. Результаты инкубации индюшиных яиц в связи с хранением // Мат. XVIII Междунар. конф. ВНАП «Инновационное обеспечение яичного и мясного птицеводства России» - Сергиев Посад, 2015. - С. 315-317.

3. Способ хранения инкубационных яиц индеек / Дядичкина Л.Ф., Позднякова Н.С., Голдин Ю.С., Юхачева Н.А., Коломейцев В.А. - 2017. - Пат. RU 2616423, приоритет 08.12.2015.

4. Elibol O., Brake J. Effect of egg position during three and fourteen days if storage and turning frequency during subsequent incubation on hatchability of broiler hatching eggs // Poult. Sci. 2008. - V. 87. - P. 1237-1242.

5. Schulte-Driiggelte R. Рекомендации по обращению с инкубационными яйцами и их хранению // Zootecnica Intl. - 2014. - №1. - С. 19-23.

6. Колокольникова Т.Н., Сунцова О.А., Полянская В.В. Изменение качества инкубационных яиц при хранении в герметичной упаковке // Вестник Бурятской ГСХА им. В.Р. Филиппова. 2019. - №3. - С. 73-79.

7. Колокольникова Т.Н., Дымков А.Б., Рехлецкая Е.К. Прием увеличения срока сбора инкубационных яиц мясных кур // Известия Горского ГАУ. - 2019. Т. 56. - №2. - С. 71-77.

8. Бурьян, М. Максимизация однородности и жизнеспособности цыплят / М. Бурьян // Птицеводство. - 2005. №6. - С. 7-9.

Для контакта с автором:

Колокольникова

Татьяна Николаевна

E-mail: kotani2009@mail.ru 


\section{The Influence of Period and Method of Storage of Turkey Eggs on the Efficiency of Incubation}

Kolokolnikova T.N.

\section{Omsk Agrarian Scientific Center}

Summary: Storage of eggs prior to the incubation is associated with changes in the internal composition and the state of the embryo. Many methods preserving the quality of the eggs and the viability of the embryos have been studied. However, as it turned out, not all storage techniques are suitable for each poultry species. Different techniques of the storage of turkey during 1-3 weeks were studied in our experiment. The storage of eggs point end up increased hatchability by 0.81-1.63\% after 1 week of storage; after 2-3 weeks of storage this technique partly alleviated the detrimental biochemical alterations in the stored egg and kept the hatchability at the level of 85.20-90.36 and 80.10-80.9\%, respectively. The use of hermetically sealed packaging for storage without sufficient airing time prior to the packaging increasingly deteriorated incubation efficiency with the increase in storage period: hatchability decreased from 89.53-91.22\% after 1 week of storage to $27.08-46.86 \%$ after 3 weeks. In any case, storage periods 2 and 3 weeks negatively affected the quality of day-old poults: increased live bodyweight at hatch by 0.05-1.45 and 0.30-4.67\% and decreased body length by 2.44-3.11 and $3.08-3.37 \%$, respectively.

Keywords: storage of turkey eggs, hatchability of eggs, live bodyweight in day-old poults, body length of day-old poults. 